\title{
ARGUMENTACIÓN, LOGOS DE LO HUMANO Y SUBJETIVISMO
}

Sumario: 1. Planteamiento del problema de si, y hasta que punto, influyen factores subjetivos en la argumentación. 2. Lucha y argumentación. 3. La doble circunstancialidad del Derecho. 4. La historicidad, el Derecho y los ideales jurídicos. 5. Logos de lo humano $y$ controversia. 6. La "circunstancia" en el logos de lo humano. 7. El perspectivismo. 8. Necesidad de diferenciar y separar el hecho de los debates en que se argumenta, frente al logos de lo razonable.

1. Planteamiento del problema de si, y hasta qué punto, influyen factores subjetivos en la argumentación

Aunque haciendo las pertinentes distinciones, Perelman ha incluido en su teoría general de la argumentación las disputas judiciales, los debates políticos - por ejemplo, en un Parlamento-, los discursos encaminados a persuadir a un grupo (mayor o menor) de gente sobre cualquier tema, la deliberación y discusión entre dos o varias personas, movidas enteramente por el sincero deseo de buena fe de hallar la solución más prudente, más plausible, más viable, y más justa, respecto de un problema ético, jurídico, político, económico, etc., y la deliberación de un solo sujeto en la que éste se desdobla en diálogo consigo mismo, animado por el óptimo propósito de resolver una cuestión en los mejores términos que le resulte posible. Además, Perelman ha subrayado que toda argumentación tiene un destinatario, al que él llama auditorio, admitiendo que dentro de este concepto puede figurar el mismo sujeto que argumente con su propia conciencia. ${ }^{1}$

1 Perelman, De la justice, Bruselas, 1945;

-Raison eternelle, raison historique, en L'hombre et l'histoire, Actes du VII ${ }^{\circ}$ Congrés des Societés de Philosophie de Langue française, Presses Universitaires de France, Paris, 1952;

- "Rhétorique et philosophie", en De la preuve en philosophie, Presses Universitaires de France, París, 1952;

- "La Justice", en Revue Internationale de Philosophie, Bruselas, 1957, fasc. 3;

- "Self-Evidence and Proof", en Philosophy, octubre de 1958;

-Logique formelle, logique juridique, Universidad de Bruselas, 1959;

- "Pragmatic Arguments", en Philosophy, enero de 1959;

- "La distinction du fait et du droit. Le point de vue du logicien", en International Review of Philosophy of Knowledge, Griffon, Neuchatel, 1960;

- "Jugements de valeur, justification et argumentation", en Revue International de Philosophie, Bruselas, $19^{6} 1$, facs. 4;

- "Ce qu'une réflexion sur le droit peut apporter au philosophe", en Archives de Philosophie du Droit, Núm. 7, Sirey, París, 1962;

- "El Idcal de Racionalidad y la Regla de Justicia", en Diánoia: Anuario de Filosofia, Centro de Estudios Filosóficos, Universidad Nacional Autónoma de México, 1.962;

- Le Fait et le Droit: Etudes de Logique Juridique, Recueil de plusieurs travaux, [163] 
Ahora bien, yo creo que conviene acentuar unas clasificaciones diferenciales, tanto respecto de los diversos tipos de argumentación y deliberación, así como también en lo que atañe a los distintos tipos de destinatario.

Por de pronto, parece claro que se debe subrayar una distinción importante. Por una parte, hay el debate en el cual cada uno de los que en él intervienen tiene por encima de todo el decidido propósito de derrotar al otro o a los otros participantes, vencerlos, y conseguir que prevalezca su propio punto de vista. Por otra parte, hay el caso del diálogo entre personas, quienes, al menos en su intención, aunque cada una de ellas tenga su propia opinión, van al debate y actúan en él, queriendo alejar de éste toda pasión. Esas personas están animadas por el deseo de que la confrontación de las diversas tesis discrepantes, pueda llevar al halltazgo de la que entre ellas resulte relativamente mejor, o de otra nueva, que supere a las que se han opuesto en el proceso de la deliberación.

Entre esos dos casos límites, se podría y se debería destacar una gama de tipos intermedios. Adviértase que he hablado, respecto del segundo tipo extremo mencionado, de un propósito de desapasionamiento, de una intención de buena fe, de un ánimo que va a la búsqueda de la objetividad; pero no he dicho que esto suceda, ni siquiera que pueda suceder, en términos totales, al cien por ciento. Quizá tal cosa sea no sólo muy difícil, sino incluso imposible. No es fácil descartar por entero la influencia de un factor emocional subconsciente que lleve al anhelo de que la propia tesis sea reconocida como la mejor.

Hay que distinguir también, desde otro punto de vista, en los debates, dos clases de ellos: aquellos que en la práctica van a ser decididos por un sujeto o unos sujetos que no actúan como disputantes, por ejemplo, por un juez, por el sufragio mayoritario de una asamblea; y aquellos otros debates en los que figuran únicamente las partes disputantes, en las cuales cada una de éstas aspira a persuadir a la otra, pero sin que haya un tercero que vaya a pronunciar una decisión. En el primer tipo, el auditorio se compone no sólo del otro disputante, sino también, además, y sobre todo, del tercero llamado a decidir. En el segundo tipo, el auditorio es, por de pronto, sólo el otro disputante.

Todas esas diferenciaciones habrán de tener un gran alcance para calibrar la mayor o menor intervención de factores subjetivos en la argumentación y el resultado de ésta.

Otro problema que quiero plantear es el siguiente. Si el hecho de que, en los asuntos humanos prácticos, haya siempre la posibilidad de un más y un menos, de una mayor o menor prudencia, de una mayor o menos plausibilidad, de una mayor o menor adecuación, de una mayor o menor pruden-

de plusieurs auteurs du Centre National de Recherches de Logique, Emile Bruylant, Bruselas, 1961 . 
cia, es debido a una deficiencia, por lo visto insuperable, del conocimiento humano; o si también, y sobre todo, eso se debe a la índole misma objetiva de los asuntos humanos. Anticipo que yo desde luego me inclino por la segunda hipótesis, la cual, sin embargo, no excluye el hecho de que debamos tomar en consideración también las limitaciones de nuestras aptitudes cognoscitivas.

Pero, antes de examinar ese segundo tema, parece adecuado que analicemos el primero, es decir, el estudio de las diferenciaciones que he subrayado desde varios puntos de vista distintos.

\section{Lucha y argumentación}

La doctrina de la argumentación, tal y como la ha desenvuelto Perelman, pretende constituir una teoria que aclare e ilumine una parte del logos, aquella parte que no tiene que ver con la evidencia; ni con la demostración estrictamente científica según las leyes de la lógica formal; ni con las verdades rigorosamente establecidas mediante la inducción en las ciencias de la naturaleza, inducción que sea desarrollada de acuerdo con los métodos lógicos y epistemológicos de ésta. Se trata de otra zona del logos, de la región del logos concerniente a la resolución de los problemas humanos de conducta práctica.

Una doctrina de la argumentación puede desenvolverse sobre una base subjetivista, o aun sin partir de una base tal, no poder rebasar el ámbito de las subjetividades, que es lo que parece que sucede en el pensamiento de Perelman.

Pero, yo entiendo que puede establecerse una teoría de la argumentación también sobre el fundamento de una aspiración a la objetividad. Claro que la prudencia, la plausibilidad, la oportunidad, la adecuación, la justicia, y la viabilidad objetivas no pueden en puridad ser absolutas, apodícticas. Si todo juicio tuviese que ser absoluto, apodíctico, entonces no habria lugar a diferenciar entre el campo de las evidencias irrefragables junto con el de las demostraciones que conducen también a evidencias tales, por una parte, y el ámbito de lo opinable, dentro del cual cabe un más o un menos de prudencia, un más o un menos de plausibilidad, un más o un menos de justicia. Pero es que sucede que en juicios concernientes a este último ámbito -al ámbito que los filósofos de la Antigüedad clásica asignaron a la dialéctica, tópica y retóricahay una superlativa complejidad de relaciones referidas a factores variables, lo cual obliga a reconocer la múltiple relacionabilidad de los juicios o de las proposiciones que se emitan en tal área.

Así, por ejemplo, podríamos ilustrar este punto con una teoría de Eduar. do García Máynez sobre los valores jurídicos. Y adviértase que García Máynez ha producido esta teoría, a mi entender plenamente correcta, como una pieza de su axiología jurídica; y que él no se ha planteado en tal doctrina el pro- 
blema del logos material de lo humano, la cuestión de la prudencia ni la de la argumentación. Dice García Máynez ${ }^{2}$ que el hecho de que los valores jurídicos sean objetivamente válidos no impide que los valores posean varias formas de relatividad. Advierte García Máynez que relatividad no significa relatizismo. El relativismo implica que los valores dependen de la opinión mudable de los hombres, mientras que, en cambio, la relatividad quiere decir simplemente que el contenido de los valores está referido a ciertas situaciones reales que son variables y cambiantes. Según García Máynez, las varias formas de relatividad de los valores jurídicos pueden ser clasificadas en tres grupos: I) Relatividad respecto de las personas. Ante todo, los valores jurídicos están referidos al hombre. Además están referidos a seres humanos, conectados bilateralmente. 2) Relatividad a situaciones concretas. Esta relatividad viene suscitada y condicionada por ciertos hechos especiales, los cuales determinan la obligación de realizar unos ciertos valores jurídicos. En este sentido, se puede decir que el Derecho Natural es diverso y cambiante, no porque los valores cambien, sino porque la materia en la cual esos valores deben ser realizados, es variable. 3) Relatividad a espacio y tiempo. Mientras que los valores en sí mismos no se dan en el espacio ni en el tiempo, por el contrario, las exigencias normativas que derivan de ellos están condicionadas por el lugar y por la época. Asi pues, la relatividad —que yo preferiría llamar relacionabilidadno es incompatible con la validez objetiva.

\section{La doble circunstancialidad del Derecho}

Por mi parte, yo concibo que las normas jurídico-positivas - tanto de las generales como de las decisiones individualizadas - no son verdades lógicas, sino que, por el contrario, son instrumentos elaborados por los hombres, para resolver problemas de convivencia y de cooperación. Por consiguiente, toda norma jurídica es la respuesta práctica a un problema práctico, sentido como de urgente solución. Reconocer esto no impide de ninguna manera que, cuando los hombres elaboran normas jurídicas incitados por una necesidad social, carezcan ellos del propósito de que el instrumento que creen para dar una solución a tales problemas sea lo más justo posible, lo más prudente que quepa, lo más adecuado que pueda darse, y cuya acción resulte tener la mayor dosis de viabilidad. Es más, eso es lo que deben hacer los hombres que afrontan tales problemas e intentan resolverlos en la práctica. Así pues, entiendo que toda norma jurídico-positiva es una especie de instrumento, de utensilio, fabricado por los hombres, con el fin de tratar determinado tipo de situaciones o de conflictos sociales, inspirándose en unos valores.

2 Eduardo García Máynez, Introducción al estudio del Derecho, $8^{\mathrm{a}}$ ed. Editorial Porrua, México, 1960. 
Por eso, una norma jurídica no puede ser verdadera ni puede ser falsa. Una norma juridica puede ser justa o injusta, conveniente o inconveniente, más o menos prudente, más o menos plausible, más o meons eficaz o ineficaz, Ahora bien, esas calidades axiológicas pueden tener un más o un menos; no pueden ser absolutas, apodícticas, exactas.

Entre la verdad y la falsedad no es posible que se den grados. Por el contrario, en la realización práctica de aquellas calidades valiosas (de justicia, prudencia, eficacia, etc.) cabe una serie de gradaciones y de matices; pero nunca la absolutez, ni los contornos tajantes y unívocos que caracterizan la evidencia lógica y la demostración cientifica.

Ahora bien, esa relatividad o esa gama de matices de la realización de las mencionadas calidades valorativas, o sea de los mencionados juicios axiológicos, no excluye la dimensión de objetividad de éstos. O expresando lo mismo con otras palabras: cuando calificamos una solución jurídica - general o individualizada - como relativamente justa, prudente, adecuada, plausible y viable, ese juicio, aunque relativo, es objetivo; porque se trata de una objetividad en la cual caben gradaciones - no en cuanto a la objetividad- sino en cuanto al grado de las realizaciones valiosas. Pero esto no implica necesariamente, en modo alguno, que tales calificaciones o tales juicios axiológicos tengan únicamente un fundamento en la subjetividad de quien los emite, no implica que sean simplemente la expresión de los mecanismos anímicos del juzgador, ni siquiera de las preferencios tan sólo subjetivas de éste.

Adviértase que todo cuanto estoy exponiendo sobre las estimaciones juridicas puede igualmente aplicarse al tratamiento de otros problemas humanos. Me refiero de modo especial al Derecho, porque, si bien el tema del logos de lo humano pretende comprender el logos de todas las acciones prácticas del hombre, estoy contribuyendo a elaborar la doctrina de ese logos, bajo el estímulo de las cuestiones jurídicas, y con el propósito de suministrar a la jurisprudencia aclaraciones que ésta necesita perentoriamente.

Volviendo ahora al campo del Derecho, las observaciones que he expuesto llevan a reconocer que toda norma jurídico-positiva está suscitada y condicionada en su orto por una determinada situación, por una circunstancia o contorno social concreto que constituye su motivación. Pero eso no es todo, hay una segunda parte estrechamente integrada con esa primera, algo así como una especie de reverso. Ese instrumento, que la norma jurídica es, ha sido elaborado para producir por tal medio unos ciertos resultados, unos determinados efectos, precisamente los efectos que el autor de la norma -general o individualizada - considera como la solución más relativamente justa, posible, como la relativamente más prudente, como la satisfactoriamente plausible, como aquella que tiene más visos de eficacia para el problema práctico planteado. 
Ese propósito significa que el criterio para determinar el ámbito de realización de la norma y para esclarecer su sentido y su alcance en cada caso, su correcta interpretación, no puede, de ninguna manera, consistir en operaciones de lógica formal. Por el contrario, ese criterio de interpretación debe consistir en anticipar mentalmente los efectos que su puesta en práctica produciría en cada caso, y en comparar esos efectos con el propósito que ha inspirado la creación de la norma en cuestión. Se debe comparar esos efectos con el propósito inherente a la norma; y, por tanto, decidir sobre su aplicabilidad a cada caso, y decidir también sobre su alcance. Todo ello se debe hacer de acuerdo con el fin de lograr, precisamente, los efectos que tal norma se ha propuesto.

Los dos puntos expuestos en el párrafo anterior llevan a subrayar la doble dimensión circunstancial de las normas jurídico-positivas - generales e individualizadas - y esa doble dimensión circunstancial no implica subjetivismo, antes bien, se da en un terreno objetivo.

Acaso convenga insistir todavía un poco más sobre la doble dimensión de circunstancialidad del Derecho, dimensión que éste comparte con todo producto cultural. Las normas del Derecho positivo son la respuesta que el legislador, o la sociedad (por vía consuetudinaria), el funcionario administrativo y el juez dan para satisfacer determinadas necesidades sociales, para resolver ciertos problemas o conflictos de la convivencia y cooperación humanas. Y, por lo tanto, es obligado tratar esos problemas o conflictos del modo como ellos se presentan en un lugar y en un tiempo determinados, inspirándose para tal tarea en las valoraciones que se estimen correctas.

Con las normas jurídicas (generales e individualizadas) sus autores se proponen la realización de un fin o resultado, cuyo cumplimiento habrá de representar el modo que se entendió como el relativamente más valioso, más justo, más prudente, o más plausible en una circunstancia concreta, para satisfacer unas necesidades o para resolver unos conflictos de la mejor manera posible. Así pues, el Derecho, al igual que otros productos culturales, es elaborado por unas gentes bajo la incitación de determinadas necesidades sentidas en un cierto tiempo y en una situación histórica concreta. Esas obras humanas representan el propósito de conseguir una finalidad, con la cual sus autores intentaron satisfacer aquellas necesidades; y esas obras fueron llevadas a cabo utilizando ciertos medios que se estimaron como adecuados y eficaces para la producción de tales obras.

Así pues, el Derecho, lo mismo que otras obras culturales tiene una doble dimensión de circunstancialidad. Por una parte, tiene una dimensión y una significación circunstanciales, en tanto que ha nacido en una situación histórica y vital concreta, para obtener, mediante los efectos que produzca, la satisfacción de unas necesidades humanas también concretas. Por otra parte, la solución que se dé a los problemas humanos tiene que ser aplicada, realizada, 
en unos hechos humanos, los cuales probablemente irán variando, cambiando, con el transcurso del tiempo; y, entonces, la solución que se dio ayer tendrá que ir siendo readaptada hoy y mañana a las nuevas modalidades de los hechos, esto es, a la nueva circunstancia.

\section{La historicidad, el Derecho y los ideales juridicos}

Esas reflexiones sobre la doble circunstancialidad del Derecho, y de la cultura en general, nos llevan a recordar un punto decisivo en el contexto del tema que es objeto de examen aquí: la esencial dimensión histórica de la vida humana.

La historicidad es debida a la combinación de lo social y lo individual. Por ser social, el hombre no estrena su vida, sino que se apoya en lo que recibe como legado cultural de los otros. Por ser individual, rectifica, innova lo recibido, inventa. El hombre es capaz de aprovechar el pasado, de beneficiarse con las conquistas logradas por sus predecesores. Pero, por otra parte, tiene la capacidad de hacerse libre de lo que fue ayer, para estar en franquía de ser de otro modo, es decir, de corregir, aumentar y mejorar la herencia cultural recibida.

La sociedad representa el papel de transmisora de los resultados conseguidos por las generaciones pretéritas y por los coetáneos. En cambio, el individuo, en tanto que tal, puede vivir por su propia cuenta, y tiene que hilar su propia existencia. Para hacer esto es capaz de liberarse del pasado, corregirlo, superarlo, aumentar el caudal de las experiencias y de los inventos, mejorar.

La historicidad humana plantea el problema de la historicidad de los ideales jurídicos, esto es, el problema de la adaptación histórica de los criterios estimativos, los cuales en sí y por sí constituyen valores jurídicos, que son ideas a priori de carácter objetivo. Mas, por otra parte, nos encontramos en la historia con una gran variedad de circunstancias, de regímenes e instituciones, todo ello diversificado simultáneamente en el espacio, y cambiante a través del tiempo.

Esa variedad y ese cambio no son sólo un testimonio de unos hechos diferentes y mudables, sino que, además, plantean exigencias normativas ideales de diversificación y de cambio para cada situación determinada y para cada momento histórico. Se trata no simplemente del hecho de la historicidad del Derecho positivo, sino también de la historicidad de los ideales. Esta segunda historicidad constituye acaso el problema más importante de la axiología jurídica.

A primera vista, puede parecer que se trata de articular armónicamente dos elementos de indole muy diferente: por una parte, ideas a priori con validez necesaria y, por otra parte, circunstancias de hecho diversas, contin- 
gentes y variables. Sin embargo, el problema no consiste en eso, antes bien, en algo diferente. El problema consiste en articular la encarnación o puesta en práctica de las consecuencias normativas de los valores, con las características concretas y particulares de cada situación histórica, en la que aquellas consecuencias deben ser realizadas o cumplidas. Se trata, pues, de un problema de realización, de materialización o corporeización en realidades históricas. Ahora bien, puesto que los valores - con validez objetiva y a priorise realizan en la vida humana, y puesto que la vida humana es esencialmente histórica, la realización de los valores tiene que ser histórica también.

Entiendo que hay cinco fuentes justificadas de historicidad para los programas ideales de Derecho, o cinco aspectos o cinco dimensiones que legitiman la historicidad de la estimativa jurídica o del Derecho natural, sin perjuicio del carácter a priori y objetivo de los fundamentos de éste. Cuatro de esas fuentes se derivan de las condiciones de la realización de los valores; por su parte la quinta fuente se funda en una multiplicidad diversa de valores concretos.

La primera fuente de historicidad de los ideales jurídicos es el hecho de que la realidad social es diversa y cambiante, lo cual afecta a la realización de los valores jurídicos, y determina que en cada caso debamos establecer normas diferentes. Hay que advertir que los valores no son todos ellos formales, antes bien, hay muchos valores jurídicos que poseen un contenido concreto.

La segunda fuente de historicidad para los ideales jurídicos consiste en la diversidad de los obstáculos que han de ser superados en cada situación, para realizar en ésta las pertinentes exigencias axiológicas —obstáculos, cuya indole determina cuáles hayan de ser los medios adecuados, es decir, inspira las varias instituciones que se configuren al servicio de la realización de aquellos requerimientos estimativos.

La tercera fuente de historicidad consiste en las lecciones sacadas de la experiencia práctica: en las enseñanzas producidas por la razón histórica, especialmente en cuanto a la adecuación de los medios para realizar un valor en una situación concreta.

La cuarta fuente consiste en las prioridades suscitadas por los diferentes grados de urgencia de las necesidades sociales, que cada situación histórica provoca; pues los hombres no pueden realizarlo todo a la vez.

La quinta fuente de historicidad no se deriva de problemas relativos al cumplimiento, ni a la realización, ni a la eficacia, sino que tiene su origen en la multiplicidad de valores que pueden resultar relevantes para el Derecho. Aunque los valores tengan una validez objetiva, ellos contienen dentro de sí mismos las referencias a situaciones concretas, a las que se hallan intrinsecamente remitidos y para las que suscitan normas específicas, esto es, directamente relacionadas con tales situaciones. Cierto que hay muchos valores 
éticos y jurídicos que se refieren a las dimensiones universales de lo humano, $\mathrm{y}$, que, por consiguiente, engendran normas ideales de aplicación general para todos los hombres y para todas las sociedades. Ahora bien, sucede que hay otros valores, los cuales, aunque poseen validez objetiva, contienen en su misma esencia una referencia particular a determinada situación concreta, a una particular condición histórica: son los valores que podríamos llamar particulares, ocasionales, situacionales y vocacionales.

Con todo lo dicho creo haber justificado que son compatibles la relatividad o relacionalidad de los juicios del logos de lo humano, los grados de mayor o menor justicia, de mayor o menor prudencia, de mayor o menor plausibilidad, de mayor o menor eficacia, con la objetividad de esos juicios. Pues se trata de la validcz objetiva de juicios relativos.

\section{Logos de lo humano y controversia}

Pero hay otro problema que he mencionado al comienzo de este artículo. A los juicios del logos de lo humano se llega muchas veces, si es que no ordinariamente, a través de un proceso de argumentación.

Hay que clasificar esos procesos de argumentación, entre otros puntos de vista, desde el siguiente: desde el punto de vista de la actitud subjetiva de las personas que debaten en un proceso de argumentación.

Señalé dos casos-límite. Uno de ellos es el de un debate en el cual cada una de las partes disputantes tiene como máximo empeño el de derrotar a la oponente y quedar ella como vencedora, cual sucede, por ejemplo, en un proceso judicial - civil o penal- entre las partes implicadas en él; o como acontece también en la discusión entre dos líderes políticos de partidos antitéticos en un parlamento, cada uno de los cuales trata a toda costa de conquistar para su tesis la mayoría de los votos.

El tipo opuesto, también caso-límite, es el del diálogo entre dos o más sabios cada uno de los cuales desea de buena fe apartar de sí toda pasión, todo interés, todo orgullo, toda vanidad, todo deseo de prevalecer, y se inspira tan sólo por el propósito de hallar, mediante la cooperación del otro o de los otros, confrontando puntos de vista y tesis diferentes, la solución más plausible, más prudente, más adecuada, más justa y más eficaz. Pero, como advertí al principio, incluso en ese segundo caso, no podemos estar seguros de que no actúen, por lo menos subconscientemente, factores subjetivos $e$ intereses individuales. Y señalé también que, claro, entre esos dos tipos límites hay una extensísima escala de grados intermedios.

Aunque esta investigación es de carácter lógico, resulta indispensable hacer algunas referencias y aclaraciones psicológicas y sociológicas.

En el primero de los tipos indicados, como uno de los dos casos-límite, 
y en aquellos otros tipos intermedios que en mayor o menor medida se acerquen al primero, hallamos el contexto real de un hecho o proceso de oposición entre quienes intervienen en el debate.

Entre los factores que actúan en un proceso de oposición, cabe mencionar los siguientes: el deseo de contradecir, de formular una protesta de inconformidad; o de hallarse inspirado por un interés antagónico al de la tesis de la otra parte; el hecho de que los participantes arrancan de convicciones antitéticas; el hecho de que tienen temperamentos contrarios; o el hecho de que se proponen metas incompatibles entre sí.

$Y$ en el caso o tipo extremo no hay solamente una oposición, sino que ésta se ha convertido en un conflicto. Cabe caracterizar el conflicto como aquel proceso de interacción en el cual los hombres contienden el uno contra el otro. En una contienda, cada una de las partes mira a la otra como adversaria. En el conflicto, la acción tiene el propósito deliberado de atacar y de derrotar a la otra parte.

En este tipo de proceso de conflicto, en realidad ninguno de los argumentantes intenta persuadir al otro, ni está dispuesto a dejarse persuadir por éste; pues ambos parten del decidido deseo de vencer, de prevalecer sobre el atro, de derrotarlo. Pero entonces la decisión no corresponde a ninguno de los argumentantes, sino que cada una de ellos se dirige a otra u otras personas, que son quien o quienes habrán de decidir, ora dando la razón al uno, ora dando la razón al otro, ora resolviendo mediante una tesis nueva que intente superar las dos o más sostenidas por los disputantes. Éste es el caso de un litigio o contienda judicial: cada una de las partes intenta vencer a la otra; pero esto puede conseguirlo tan sólo mediante la decisión del destinatario de la argumentación, es decir, mediante el fallo del juez. Éste es también el caso de dos oradores políticos en un debate parlamentario, cada uno de los cuales trata de persuadir no al otro, sino a la mayoría de los que integran la asamblea, sin excluir la posibilidad de que surja un tercero que defienda una nueva tesis mixta, de transacción o diferente, y que sea este tercero quien consiga persuadir a la mayoria.

En este tipo de procesos de argumentación, cada una de las partes disputantes se desenvuelve con un criterio cerrado, que de antemano excluye abrir su mente a los argumentos del otro, pues el propósito consiste en persuadir al tercero en discordia (juez, mayoría, etc.).

En el otro tipo o caso-límite indicado, la situación es muy diferente de la que se da en el primero. Aquí, en ese segundo caso-límite, se trata de dos o más personas, cada una de las cuales se halla sinceramente inspirada por el honesto deseo de hallar la mejor solución para un problema. Cada uno de los dialogantes o deliberantes puede, por lo menos al principio del debate, sostener una tesis diferente de la mantenida por el otro o los otros que intervienen en la discusión; pero sin que se sienta animado por el propósito de 
mantener a todo trance y hacer triunfar su tesis propia. Por el contrario, con gran amplitud de criterio e inspirados por una auténtica buena fe, los dialogantes se hallan dispuestos a abrir los poros de su propia mente a los argumentos contrarios, pues la intención que tienen no es la de prevalecer, sino tan sólo la de hallar la mejor solución posible al problema planteado.

A primera vista, podría tal vez creerse, pero tal creencia es errónea, que en el primero de los casos límites, el proceso de la confrontación de argumentos se halla expuesto al peligro, tal vez fatal, de que se interfieran las pasiones. subjetivas $\mathrm{y}$, por consiguiente, de que la solución que se logre se apoye tan sólo o predominantemente sobre una actitud pasional, la cual puede estar carente de toda justificación objetiva. Y, sin embargo, las cosas no son así; pues por mucho que sea el derroche de pasión que hagan los disputantes, y la unilateralidad a que les lleve el propio interés de cada uno, la decisión no corresponde a los disputantes, sino a un tercero. El único peligro aquí sería que una de las partes disputantes consiguiese contagiar su pasión al tercero imparcial que debe resolver.

En cambio, en el otro caso-límite opuesto, en el del diálogo entre sabios de buena fe, cada uno de éstos tiene la óptima intención de hallar la más plausible de las soluciones. Por eso, la intervención de los factores subjetivos es muchísimo menor que en el otro tipo de ejemplo. Claro que, aunque esa interferencia de las tendencias y emociones subjetivas sea mínima, hay más riesgo de que pueda introducirse un factor subjetivo en la decisión, precisamente porque ese factor actúa subrepticiamente en el plano de la subconsciencia.

Ese factor subjetivo puede consistir en elementos diferentes, por ejemplo: la simpatía personal que un interlocutor despierte en su oponente; también, la acción de la elocuencia fascinante de uno de los interlocutores; asimismo, la influencia del deseo, advertido (intencional) o inadvertido (por temperamento), de llegar a una transacción o compromiso, incluso sacrificando las tesis que ese interlocutor considere como justificadas. Nótese que en ese tipo de proceso argumentativo estudiado ahora, la decisión no corresponde a un tercero, sino que se busca que ésta se produzca por acuerdo común.

En el gran número de tipos intermedios entre los dos extremos hasta aquí estudiados, conviene destacar el siguiente: el caso de una persona de espíritu abierto, la cual, aunque intimamente persuadida de su propia tesis, está dispuesta a escuchar de buena fe los argumentos contrarios que sostiene otra persona. En principio, aquella persona, en tanto que convencida del acierto de su propia tesis, desea mantenerla y conservarla; pero, por otra parte, se expone al riesgo de que los argumentos de la otra parte la persuadan. Adviértase, además, que el mismo peligro corre la otra persona que va a tratar de convencer a la primera, el peligro de que ésta, la primera, la convenza a ella.

Un caso similar a éste es el hecho de que dos personas con actitudes y 
con estados de ánimo similares a los de los dialogantes del ejemplo que acabo de exponer, se avengan a llevar su disensión ante el juicio de un tercero que escuche imparcialmente las argumentaciones de ambas partes. La diferencia que se da entre este ejemplo y el primero de los casos límites antes analizado -el de los litigantes apasionados-, es la siguiente: en el caso que acabo de indicar, las dos personas argumentantes, aunque cada una de ellas se sienta de antemano intimamente persuadida por su propia tesis, admite la posibilidad de que la tesis de la otra parte sea mejor, y se aviene a someter la discordancia al criterio de un tercero; mientras que en el tipo límite antes analizado, cada uno de los litigantes tiene el prejuicio y ha tomado la determinación previa de rechazar la tesis del otro.

Creo haber mostrado y justificado que la relatividad o relacionabilidad de la razón argumentativa o del logos de lo razonable no excluye la validez objetiva de ese logos; si bien tal validez objetiva se da dentro del marco de la circunstancialidad - también objetiva - que encuadra ese tipo de razonamiento.

\section{La "circunstancia" en el logos de lo humano}

La circunstancia, siempre concreta, dentro de la cual se desenvuelve el logos de lo razonable o de lo humano y el proceso argumentativo, consta de múltiples y muy variados componentes: la situación histórica efectiva en la cual el problema se plantea; el grado de urgencia, de perentoriedad, o la escala de prioridad o de preferencia con que se manifiestan las necesidades que suscitan el problema; los puntos de referencia suministrados por una tradición todavía vigente; el hecho de las conviciones predominantes en el medio que circunscribe el razonamiento; y también, y sobre todo, la perspectiva de las personas que deliberan o de las personas que argumentan. Por de pronto, este último componente merece comentario especial y aparte.

Ante todo, no se olvide que aquí estamos tratando de algo que es logos, que es lógica, pero un logos o una lógica muy diferente de la lógica pura tradicional, de tipo físico-matemático. Al fin y al cabo, mis reflexiones sobre el logos de lo humano o de lo razonable están emparentadas con la doctrina de José Ortega y Gasset sobre la razón vital y la razón histórica, de la cual pretenden constituir una derivación, o, mejor dicho, un ulterior desenvolvimiento.

Se trata de un tema de lógica, pero de lógica de lo humano. Y, como ha dicho Ortega y Gasset, "Lo humano se escapa a la razón físico-matemática como el agua por una canastilla." Ahora bien, sucede que cuando las varias doctrinas sobre las ciencias del espíritu criticaron el "naturalismo de la razón físico-matemática indebidamente aplicada al campo de lo humano, e intentaron intelectualizar lo humano en un cien por ciento, también fracasaron 
del modo más rotundo. Aquellas doctrinas sobre las ciencias del espíritu concibieron y quisieron ver lo humano como idea, como un sistema de ideas, fijo y preestablecido. Si alguno, como Hegel, habla de un movimiento del espíritu, tal movimiento es cosa ficticia, porque se trata del desenvolvimiento de lo que ya está definitivamente comprendido en ese sistema, se trata del desarrollo de la estructura dialéctica, que ya está determinada en la estructura misma del espíritu. Ese tipo de ciencias del espíritu no estudió el hecho humano en su auténtica realidad, tal y como ésta sea, sino que trató de encajarlo arbitrariamente en la urdimbre de un sistema de ideas. No trató de averiguar el sentido real, la significación efectiva de los hechos históricos, sino que insufló violentamente en éstos un sistema lógico, preconcebido, una construcción de ideas preestablecidas". ${ }^{3}$ Si resultaba que lo humano -o lo histórico, que para el caso es decir lo mismo- no se ajustaba a los cuadros de ese sistema de ideas, entonces se mutilaba lo humano, se deformaba el hecho histórico, se le retorcía o falseaba, hasta conseguir que encajara en aquellos cuadros intelectuales.

Repito que lo mismo la razón vital e histórica de Ortega que mi doctrina del logos de lo humano o de lo razonable, la cual es una especie de lógica de la acción, es estricta, rigorosamente, razón, ratio, logos, rigoroso concepto.

Pero claro que a esto entiendo que debe añadirse que el rigor de la razón vital e histórica, o del logos de lo humano o de lo razonable, no implica exactitud, no implica evidencia incontrovertible. No implica nada de eso, precisamente porque su objeto, la acción humana, la existencia humana, no posee las características de deducción sistemática y exacta que caracteriza a la lógica formal y a la matemática.

Como he indicado ya, la historicidad es una dimensión esencial de la humana existencia. Ahora bien, sería insensato suponer que la historicidad impide la validez de juicios de valor, de estimaciones con fundamento objetivo.

\section{El perspectivismo}

Ahora hay que insistir en una esencial dimensión de la vida humana, y, por tanto, también del logos de lo humano y de lo razonable y del proceso de la argumentación: la dimensión de perspectivismo.

El perspectivismo rechaza simultáneamente tanto el subjetivismo (que, a fuer de escepsis, es suicidio del espíritu) como también el racionalismo abstracto absolutista (negador de la vida, incapaz de explicar el abigarrado paisaje de la historia). El perspectivismo supera la antítesis entre esas dos posturas, estableciendo una nueva y superior actitud. Ortega y Gasset ha enseñado que el sujeto no es un medio transparente, un yo puro inmutable que

3 José Ortega y Gasset, Obras Completas, tomo VI, pp. 32 ss., Ed. de la Revista de Occidente, Madrid, 1947 . 
refleje la realidad, sino que impone a ésta en alguna medida su modo propio de ser; pero esta configuración de la realidad por parte del sujeto no implica, de ningún modo, una deformación o falseamiento de ella. Cuando interponemos, en la corriente de un río, una red de pescar o una alambrada, selecciona ésta algunos de los elementos que la corriente traía consigo. Ésta es la función que cada hombre y cada época opera con la realidad y con los valores que le circundan. De la infinitud de elementos que integran la realidad, el sujeto capta un cierto número de ellos, cuya forma y contenido coinciden con la malla de sus intereses y preferencias. Esto mismo acontece, en mayor volumen, con cada pueblo y, sobre todo, con cada época. Todos los sujetos, pueblos y épocas tienen su especial participación en la verdad y en los demás valores. Cada conciencia aprehende la realidad desde un punto de vista que le es privativo. Cuando varios hombres contemplan desde puntos de vista diversos el mismo paisaje, éste se organiza ante sus respectivos ojos de diversa manera; pero ello no supone que tales visiones diferentes sean falsas o ilusorias; cada una de ellas es legítima. Toda vida es un punto de vista, una perspectiva sobre el universo. Lo falso seria que cada perspectiva pretendiera ser ella la única verdadera. Lo que es verdad es el perspectivismo, el cual muestra parcialmente justificadas diferentes perspectivas.

Adviértase que nuestra vida es una rara, una peregrina realidad, una realidad dual, que consiste en hallarnos reciprocamente de modo inseparable el mundo y yo. Mi vida no soy yo, ni es tampoco el mundo. La vida es correlación entre el yo y su mundo. La vida es conciencia de mí mismo, pero no únicamente de mí mismo solo, sino a la vez del mundo conmigo; y es, además, tráfico constante de mí mismo con el mundo; porque el ser de mi vida tengo que hacerlo yo, tengo que irlo tejiendo en la elaboración constante de mi comportamiento, de mis haceres, echando mano de alguna de las posibilidades que se me ofrecen en mi contorno. Mi vida es ese trato con el mundo, mejor dicho, con mi mundo: yo estando en el mundo, en mi mundo, pensando en él, ocupándome con él; es, en suma, la conjunción correlativa del sujeto con un mundo de objetos, en la cual el yo va fabricando la trama de su existencia, dentro de la holgura y variedad que el contorno le brinda.

Eso que llamo el mundo, en realidad es mi mundo. Ese mi mundo se halla constituido por ingredientes objetivos, es decir, que no están creados por mi, aunque sí están organizados correlativamente a mi yo, es decir, en una especial perspectiva. El sujeto no es un puro espejo que refleja la realidad, no es un sujeto puro, idéntico a los demás sujetos e invariable, antes bien, ejerce sobre los objetos una actividad seleccionadora, según sus propias preferencias atencionales, y una actividad organizadora de su perspectiva. Así pues, el mundo, mejor dicho, el mundo de una persona, tal y como ella lo tiene ante sí, resulta de esa acción seleccionadora y de esa organización de la perspectiva. Hay, pues, una estricta correlación entre el yo y su mundo, 
tanto en el campo del conocimiento teórico como en el ámbito de la acción práctica.

La correlación entre el sujeto y los objetos de su mundo, y la interacción entre ambos, no impiden establecer la diferencia entre la verdad y el error, entre lo valioso y lo antivalioso, entre lo prudente y lo menos prudente o lo no prudente, entre lo más y lo menos plausible. Esa correlación no es de ninguna manera una invitación al escepticismo, ni siquiera en la forma camuflada o hipócrita que éste presenta en el subjetivismo, antes bien todo lo contrario. Porque al descubrir y subrayar los factores que condicionan cualquier objeto pensado, cualquier decisión tomada o cualquier conducta puesta en práctica, se hace posible aquilatar con precisión el alcance de cualquier conocimiento, de cualquier decisión y de cualquier conducta. En efecto, cuando descubrimos el punto de vista de la referencia de un sujeto a determinados objetos o temas, y los factores que influyen sobre esa perspectiva, podemos entonces calibrar el alcance y el significado de aquellos objetos o temas. Aunque su alcance y su significado sean parciales, condicionados por la perspectiva, esto no les resta objetividad, se entiende, en su parcialidad y en su dependencia. Pero es que todo conocimiento humano ès parcial, y depende de un punto de vista y también de los factores que operan en la determinación de éste. El conocimiento absoluto, ubicuo, sub specie aeternitatis, sólo puede ser propio de Dios. Incluso podría decirse que el mundo en sí, pleno, sin limitaciones de punto de vista, es decir, visto desde todos los puntos de vista a la vez, en verdadera totalidad, tan sólo puede ser el correlato de la Conciencia Divina.

Así pues, mi mundo, aunque esté compuesto de ingredientes reales y objetivos, aparece necesariamente como un correlato del yo, de mi yo, aparece como mi mundo. De tal guisa, la conciencia - la conciencia individual y concreta de cada individuo- es ineludible y necesariamente el centro nato del universo; puesto que la visión del mundo se articula en una perspectiva que converge de modo forzoso en mi pupila mental que lo contempla, y en su acción que tiene que habérselas con él, que tiene que tratar con él. La perspectiva creada por el sujeto es ineludible y necesaria: constituye uno de los componentes de su mundo, es decir, del mundo que está ante el sujeto, y que le plantea problemas a éste.

Pero, claro es que, aun cuando cada sujeto implica una perspectiva individual, propia, exclusiva, no obstante, entre los sujetos pertenecientes a una misma situación histórica - a un mismo pueblo y a una misma época- participantes en un mismo patrimonio cultural, se dan notorias e importantísimas analogías, denominadores comunes de gran alcance. Esto nos permite señalar ya no tan sólo perspectivas individuales, sino perspectivas socio-cultural-históricas, una especie de contexto común. Esto es precisamente lo que hace posible el diálogo, el cual sería impracticable si no existiese entre los 
dialogantes y los destinatarios de sus argumentos, un marco común de referencia, un fondo análogo de ciertas convicciones básicas, un mismo patrimonio de algunas ideas, y especialmente de valoraciones.

Ahora bien, aunque la perspectiva venga en parte determinada por la acción de algunos factores subjetivos, sin embargo, hay que diferenciar entre aquello que se produce como resultado objetivo de una perspectiva, frente a la interferencia de factores emocionales o pasionales puramente arbitrarios o fortuitos. Éstos distorsionan la visión de la objetividad en una perspectiva, determinada por una conciencia que proceda de buena fe al servicio de la captación mental o de la puesta en práctica de unos valores.

8. Necesidad de diferenciar y separar el hecho de los debates en que se argumenta, frente al logos de lo humano o de lo razonable

El factum de que los hombres discuten sobre problemas de conducta práctica humana y al debatir sobre ellos argumentan con razones referentes a la justicia, la prudencia, la plausibilidad, la adecuación, la oportunidad, la eficacia, etc., plantea el problema filosófico de averiguar qué clase de razonamientos sean los empleados en tales debates, de analizar y comprender los componentes y la estructura de tales razonamientos.

Pero no podemos identificar el hecho de esos debates, de esas disputas, hecho en el cual puede intervenir una serie de factores accidentales -entre ellos, de arbitrario subjetivismo-, con la indole y la justificación del logos empleado en esas disputas, de la argumentación, estudiada por Perelman, o de lo que a mí me agrada mejor llamar logos de lo humano o de lo razonable.

El factum referido pone en evidencia que real y efectivamente los hombres argumentan. Éste es el punto de partida para una reflexión filosófica. Pero lo que la reflexión filosófica se propone es investigar la naturaleza de lo argumentativo y, sobre todo, averiguar los criterios para juzgar el valor objetivo de los argumentos, los títulos de convicción de éstos, el grado de mayor o menor justificación de tales argumentos.

Adviértase que quienes argumentan pretenden que lo sostenido por ellos es mejor que lo defendido por los otros argumentantes.

Así pues, lo que propongo es diferenciar entre el fenómeno de la disputa, de la discusión, del debate, en el cual se argumenta por las dos o más partes que intervienen en él, por un lado, y, por el otro lado, la razón argumentativa, que arranca del dato del problema práctico, y que pondera la situación de éste, analiza y sopesa todos los factores que en ésta concurren, y trata de inspirarse razonablemente en valores de justicia, prudencia, oportunidad, adecuación, viabilidad, etc., y que intenta además anticipar mentalmente los probables efectos que en la realidad vayan a tener respectivamente las varias propuestas. 
En el hecho del debate o de la disputa pueden concurrir, y habitualmente concurren, factores subjetivos pasionales, de temperamento, de interés, de concupiscencias o apetitos, etc. $\mathrm{Y}$ esos factores pueden determinar que el sujeto sobre el cual influyan se salga propiamente del campo de una dialéctica honesta y degenere en una actividad de tipo sofístico. Pero, con independencia de la acción de tales factores, cabe proceder al análisis o examen de los argumentos, considerados éstos en sí mismos, como una clase especial de logos, el logos de lo humano o de lo razonable.

Respecto de aquellos factores pasionales, apetitivos, de interés, que se interfieran, hay que distinguir tales factores frente a la perspectiva que toda conciencia implica - lo mismo toda conciencia individual, que el punto de vista característico de las convicciones predominantes en una determinada situación histórica.

La perspectiva es una dimensión inevitable, esencial a toda mente humana - lo mismo en el conocimiento puramente teórico, que en los enfoques prácticos de los problemas de comportamiento. La perspectiva, según he explicado ya, no implica de ninguna manera que ella necesariamente falsee o deforme los objetos o los temas contemplados a través de ella. Por el contrario, las pasiones y concupiscencias interferentes, éstas sí pueden traer consigo un falseamiento o una deformación.

En fin de cuentas, lo que se trata de plantear aquí no es una investigación psicológica de la argumentación. Se trata de una cosa diferente: un análisis o examen de la razón argumentativa, del logos de lo humano o de lo razonable, considerado éste en un plano de objetividad.

Claro que la "objetividad" hay que entenderla no en un sentido abstracto, utópico y ucrónico, antes bien, como una objetividad intravital, como una objetividad doméstica a la humana existencia. Lo que en otros trabajos míos he dicho sobre la objetividad intravital de los valores, entiendo que tiene no sólo aplicación a éstos, sino también a todo el logos de lo humano.

Que los valores y el logos de lo humano son objetivos significa que ellos no son meramente subjetivos, es decir, significa tan sólo que no consisten en el resultado de mecanismos psíquicos. Considero que esa objetividad no debemos concebirla, como tuvieron la tendencia a hacerlo respecto de los valores Scheler y N. Hartmann, a manera de una especie de objetividad ideal abstracta, lo cual suscitó el gracioso e irónico comentario de Heidegger de que aquellos filósofos habían elaborado una "astronomía de los valores", es decir, una especie de utopía y ucronía de los valores, considerando éstos como puras esencias ideales.

Entiendo que los valores y el logos de lo humano son objetivos, en el sentido de que no son meras emanaciones del sujeto, en el sentido de que no son leyes ni hechos causales de naturaleza psicológica, ni meros caprichos, ni tampoco la expresión de simples convicciones sociales. Pero la objetividad 
de los valores y del logos de lo humano o de lo razonable se da dentro del marco de la vida humana. Es decir, se trata de una objetividad intravital. Son objetivos, porque no son producidos por el sujeto. Son objetivos, porque constituyen "razones" con cuya validez, o con cuya plausibilidad, el sujeto tropieza, al igual que tropieza con otros objetos. Esta objetividad es tal, dentro de la vida humana, para el hombre. Y me refiero a la vida o existencia humana en el sentido de la filosofía de José Ortega y Gasset, es decir, del humanismo trascendental.

Esta metafísica orteguiana de la vida no es subjetivismo, ni idealismo, como tampoco es realismo. No es subjetivismo ni idealismo, porque precisamente descubre que la vida es coexistencia del yo y de los objetos reciprocamente condicionados el uno y los otros. Mi vida requiere de estos dos ingredientes esenciales. El mundo y yo somos como gemelos inseparables; pero los objetos del mundo, o mejor dicho de mi mundo, lo mismo que el yo, se dan en la realidad de mi vida, que es la realidad indubitable, y que es también la realidad que sustenta y condiciona todas las demás realidades.

Tal vez - aunque yo no me atreva a afirmarlo categóricamente- las verdades lógicas, las matemáticas y otras similares, aquéllas dotadas de evidencia inmediata, o justificadas por demostraciones rigorosamente deductivas, tengan una validez ideal independientemente del sujeto. Pero, en cambio, los valores y las razones del logos de lo humano, poseen una objetividad, que es inmanente a la existencia humana, una objetividad intravital, están referidos a esa vida humana. Son objetivos, porque no dependen del sujeto; pero objetivamente están referidos a la vida del hombre, y no sólo a la vida del hombre en general, sino también a las situaciones particulares de la vida. El valor y el logos de lo humano, son válidos no porque el sujeto les otorgue esa calidad mediante y en virtud de su agrado, de su deseo o de su interés. Pero los valores y el logos de lo humano tienen sentido en el contexto de la vida humana. Creo que tiene razón Risieri Frondizi ${ }^{4}$ al sostener que no se puede separar radicalmente, por entero, el valor y la valoración.

$Y$ lo mismo debe decirse respecto de los argumentos razonables: no se puede separar radicalmente, por entero, la razón razonable y el sujeto que razona o argumenta. Al emplear la expresión "razón razonable", que a primera vista pudiera parecer un pleonasmo, trato de referirme al campo de lo "razonable" como algo diferente del ámbito de lo "racional", tal y como lo he expuesto en otras publicaciones mías anteriores.

Y debo insistir en que los valores y las razones del logos de lo humano se dan objetivamente no sólo dentro del marco y del contexto de "situaciones concretas". Cada situación concreta comprende la conjugación del yo y de su circunstancia objetiva. $\mathrm{Y}$ es así, porque nuestra vida constituye siempre una relación inescindible y dinámica entre el sujeto y su mundo.

* Risieri Frondizi, ¿Qué son los valores?, Fondo de Cultura Económica, México, 1957. 
Los valores y el logos de lo humano tienen una entidad o consistencia más allá de nuestra mente; pero no son independientes de la humana existencia, antes bien, tienen sentido en el contexto de ésta. En efecto, los valores y las "razones", y los argumentos, cobran sentido para el hombre en relación con los componentes de su mundo o circunstancia y en la relación de éstos con los sujetos humanos en una determinada situación.

Tal vez, la vía correcta para expresar esta concepción sería la de señalar que los valores y las razones "razonables" tienen una objetividad relacional en el contexto de la vida humana, de la vida humana en general y, además, en el contexto particular de cada una de sus situaciones concretas. Por lo tanto, se trata de una objetividad pluri-relacional.

LuIS Recaséns Siches

Instituto de Investigaciones Filosóficas

Universidad Nacional Autónoma de México 